\title{
Uncertain Range Physical Quantity Time Data Type
}

National Cancer Institute

\section{Source}

National Cancer Institute. Uncertain Range Physical Quantity Time Data Type. NCI

Thesaurus. Code C95697.

A data type comprised of an uncertain range of integers that are comprised of a measured physical entity with units that describe a period of time. 